\title{
Temporary corneal oedema after acute intake of alcohol
}

\author{
TAKASHI SHIONO, YOSHIHIRO ASANO, TAKAKO HASHIMOTO, \\ AND KATSUYOSHI MIZUNO
}

From the Department of Ophthalmology, Tohoku University School of Medicine, Sendai 980, Japan

SUMMARY A 65-year-old man had diffuse, bilateral corneal oedema after acute intake of alcohol. Three days later the total opacification began to clear from the peripheral area towards the centre of the cornea. One month later both corneas were completely clear, and visual acuity was 20/20 in both eyes. Specular microscopy showed in the right eye greatly enlarged endothelial cells, which subsequently shrank, and they showed some pleomorphism six months later. The pleomorphic endothelial cells in the left eye changed little with time. Our findings suggested that the corneal oedema in this patient resulted from temporary endothelial dysfunction with extensive cell loss.

It is well known that the acute intake of alcohol causes a disturbance of vision related to damage of the optic nerve.' To our knowledge no reports have described temporary corneal oedema from acute ingestion of alcohol. We describe such a case in a $65-$ year-old Japanese man.

\section{Case report}

A 65-year-old man drank about 1.01 of distilled Japanese sake on 15 October 1984 and lost con-

Correspondence to T Shiono, MD.

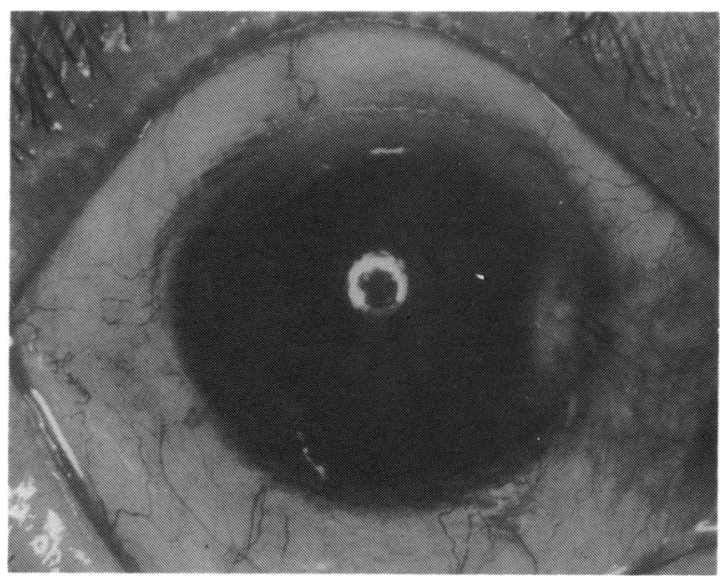

Fig. 1 Corneal oedema was apparent in the right eye on the first hospital day. sciousness. The next day he was admitted to hospital for continued unconsciousness, dyspnoea, and cyanosis. Hypoglycaemia $(16 \mathrm{mg} / \mathrm{dl}(0.89 \mathrm{mmol} / \mathrm{l})$ and an elevated aspartate transaminase level $(258$ $\mathrm{KU})$ were found. The results of the following tests were normal: renal function, haemogram, and blood ammonium concentration. No signs of infection were found.

On a diagnosis of hypoglycaemia-induced unconsciousness the patient was given an intravenous drip injection of glucose and oxygen inhalation. His blood glucose concentration increased to $104 \mathrm{mg} / \mathrm{dl}(5 \cdot 8$

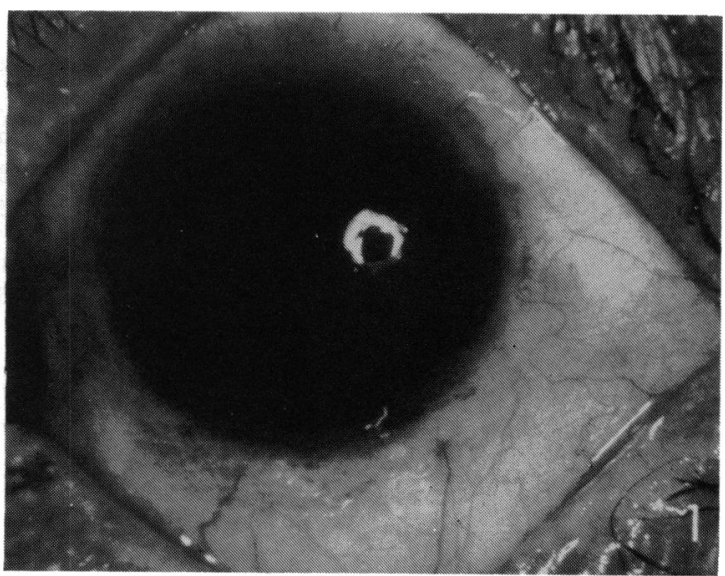

Fig. 2 Corneal oedema was also observed in the left eye, though it was milder than in the right eye. 


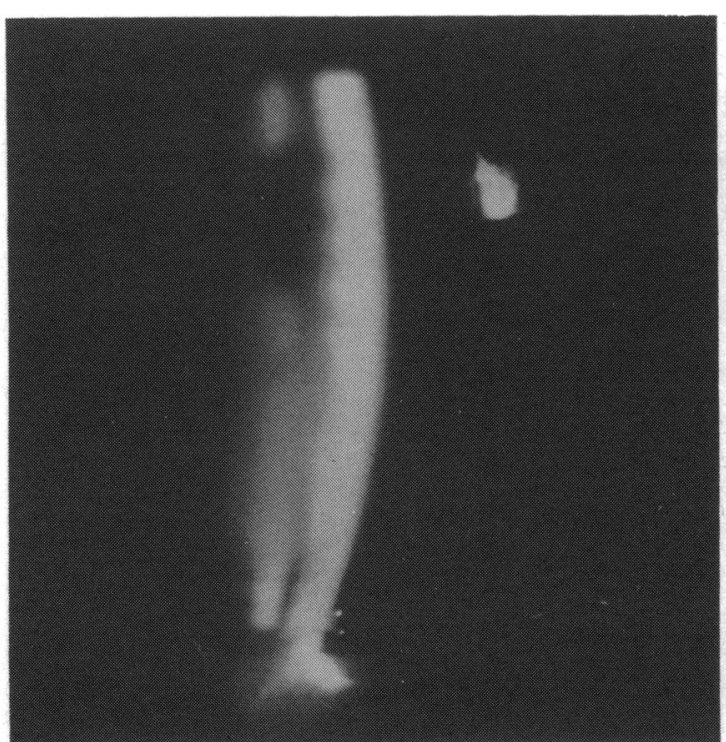

Fig. 3 Total corneal opacity begins to clear in the peripheral area of the right cornea on the third day in hospital.

$\mathrm{mmol} / \mathrm{l}$ ), he became conscious, and his cyanosis improved. On 17 October 1984 he noticed blurred vision in both eyes and was referred to our clinic. No lubricating drops had been applied nor had he used contact lenses. He had no history of ocular disease. Our examination showed a visual acuity of counting fingers OD and 10/200 OS, with best correction. Slitlamp examination of the anterior segment disclosed bilateral corneal oedema (Figs. 1 and 2). Pachometry

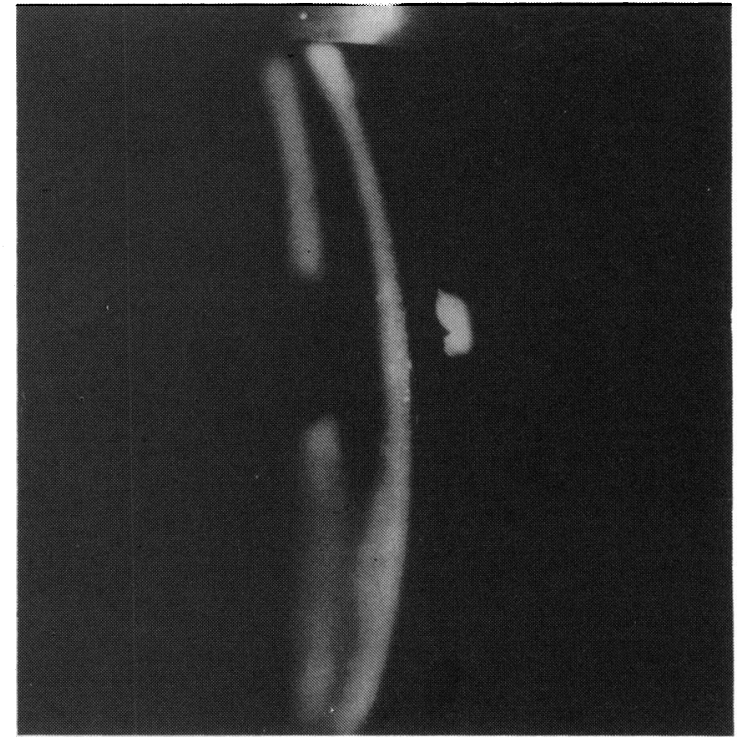

Fig. 4 An area in the upper half of the left cornea starts to clear on the third day in hospital.

showed the corneas to be $0.73 \mathrm{~mm}$ thick in both eyes (about 1.5 times normal). Intraocular pressures were within normal limits. There were no abnormal findings in the lens, vitreous, or fundus in either eye.

On the diagnosis of idiopathic corneal oedema the patient was treated with vitamins $\mathrm{A}$ and $\mathrm{B}$ complex $\left(B_{1}, B_{6}, B_{12}\right)$, and topical application of $0 \cdot 1 \%$ dexamethasone and $0.05 \%$ vitamin $B_{2}$ eye drops three times a day. After three days the corneal oedema

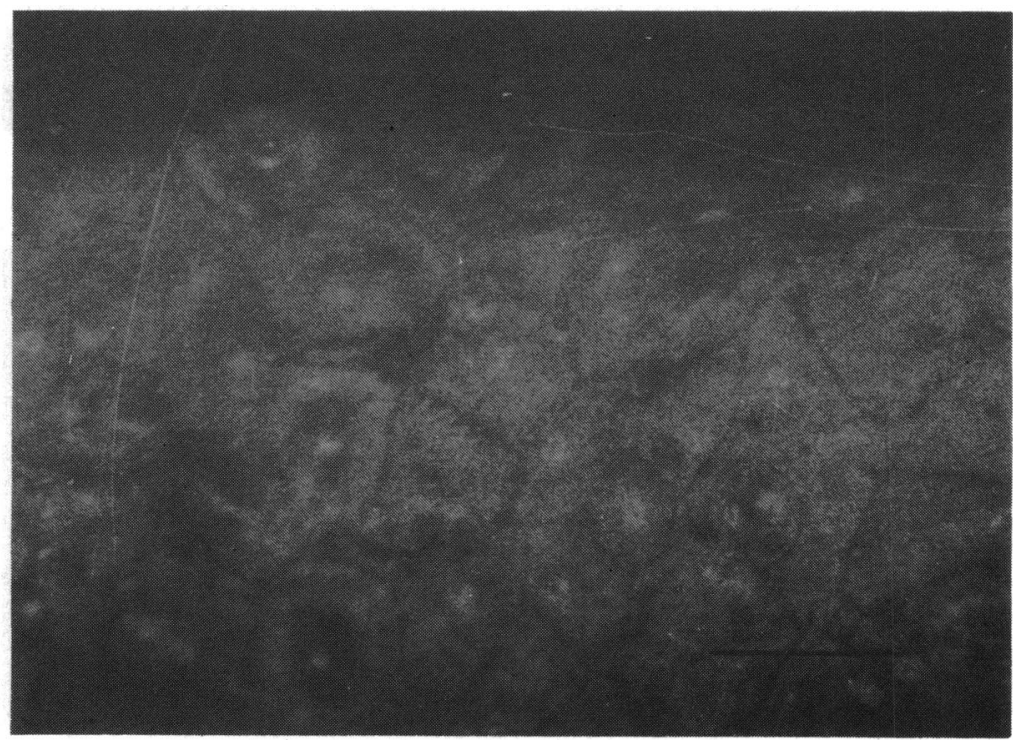

Fig. 5 Extremely enlarged endothelial cells were found in the right eye. Bar $=100 \mu \mathrm{m}$. 
Fig. 6 Pleomorphic endothelial cells were noted in the left eye. Bar $=100 \mu \mathrm{m}$.

Fig. 7 At six months greatly enlarged endothelial cells have shrunk, but some pleomorphic cells persist in the right eye. Bar $=100$ $\mu \mathrm{m}$.

Fig. 8 At six months pleomorphic endothelial cells are unchanged in the left eye. Bar $=100 \mu \mathrm{m}$.
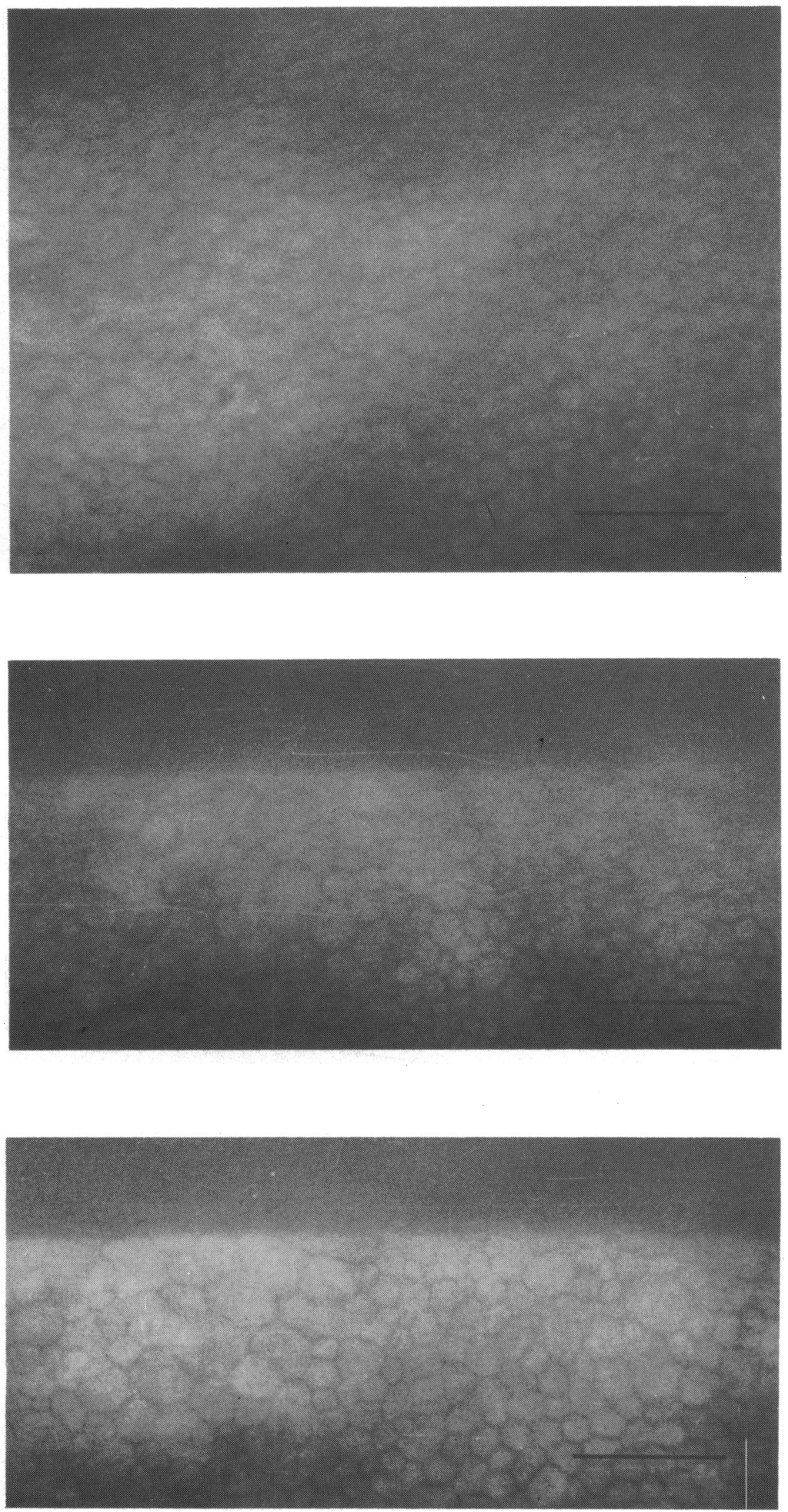
began to decrease at the periphery (Figs. 3 and 4), the decrease continuing to the centre of the cornea. The right eye improved at a slower rate than the left. One month later both corneas were entirely clear, and visual acuity was $20 / 20$ bilaterally.

Specular microscopy done on the fifth day after admission showed extremely enlarged endothelial cells in the right eye (Fig. 5) and pleomorphic endothelial cells in the left eye (Fig. 6). Specular microscopy repeated at six months showed that greatly enlarged cells in the right eye had mostly disappeared, though some large pleomorphic cells were noted (Fig. 7). The endothelial cells in the left eye remained pleomorphic (Fig. 8).

\section{Discussion}

Our patient had temporary corneal oedema after acute intake of alcohol. The initial specular microscopic observations showed extremely large endothelial cells in the right eye, which subsequently shrank, leaving some pleomorphic features; in the left eye pleomorphic endothelial cells remained unchanged with time. Interestingly, the peripheral area of the corneas started to clear first and the clearing then spread to the centre. These findings suggest that the transient corneal oedema in our patient was caused by temporary dysfunction of the corneal endothelium, with some loss of endothelial cells, particularly in the central area of the right eye. The difference in the severity of the cell damage between both eyes corresponded to the observed clinical course: the corneal oedema resolved in the left eye sooner than in the right eye.

It is unlikely that ethanol is directly toxic to the corneal endothelium, because similar reports of this condition are lacking in alcoholic patients. Moreover, no damage of the corneal endothelium was produced in experimental intraperitoneal injections of ethanol. ${ }^{2}$ The prolonged hypoglycaemic condition of this patient may have been a factor in causing the oedema. His hypoglycaemia might have resulted in the very low aqueous glucose level, as the glucose concentration in aqueous humour ${ }^{3}$ has been reported to be about $60 \%$ that of the glucose serum level. Because glucose has been reported as one of the important factors in the maintenance of the endothelial function of cornea ${ }^{4}$ it is possible that the prolonged hypoglycaemia was a factor causing the corneal damage in this patient. It also seems possible that prolonged exposure of the eyes and hypoxia during his stupor were other factors that caused the corneal damage, though there may have been other unknown factors. Cyanosis was noticed in this patient and improved with oxygen inhalation. The combination of these factors may thus have caused the corneal damage.

\section{References}

1 Grant WM. Ethyl alcohol. In: Grant WM, ed. Toxicology of the eye. Springfield: Thomas, 1962: 340-8.

2 Leibowitz HM, Ryan W, Kupherman A, Vitale JJ. The effect of alcohol intoxication on inflammation of the cornea. Arch Ophthalmol 1985; 103: 723-5.

3 Davies PDD, Duncan G, Pynsent PB, Lucas VA. Aqueous humour glucose concentration in cataract patients and its effect on the lens. Exp Eye Res 1984; 39: 605-9.

4 Glasser DB, Matsuda M, Ellis JG, Edelhauser HF. Effect of intraocular irrigation solutions on the corneal endothelium after in vivo anterior chamber irrigation. Am J Ophthalmol 1985; 99: 321-8.

Accepted for publication 31 July 1986. 